\title{
Historical geography and environmental history in China
}

\author{
Zhaoqing Han
}

Correspondence:

zhqhan@fudan.edu.cn

Center for Historical Geographic

Studies, Fudan University, 220

Handan Road, Shanghai 200433,

China

\begin{abstract}
This paper was originally prepared for a roundtable on "Chinese Environmental History: Current Research and Future Prospects" at the Eighth International Convention of Asia Scholars. This is a large and complex topic covering a broad range of disciplines. Except for those publications which clearly marked their titles as "environmental history," it is difficult for us to classify which is indeed a study of "environmental history," let alone provide a comprehensive summary of the current research of Chinese environmental history. However, I would like to share with you my view on this topic from the perspective of historical geography. This paper consists of the current research of Chinese environmental history, its relationship with Chinese historical geography and my view on its future prospects.
\end{abstract}

Keywords: Environmental history, Historical geography, Relation, Future prospects

\section{Background}

This paper was originally prepared for a roundtable on "Chinese Environmental History: Current Research and Future Prospects" at the Eighth International Convention of Asia Scholars. This is a large and complex topic covering a broad range of disciplines. Except for those publications which clearly marked their titles as "environmental history," it is difficult for us to classify which is indeed a study of "environmental history," let alone provide a comprehensive summary of the current research of Chinese environmental history. However, I would like to share with you my view on this topic from the perspective of historical geography. This paper will begin with an introduction of the current research of Chinese environmental history, then move on a discussion of its relationship with Chinese historical geography, and finally it will conclude with the author's view on its future prospects.

\section{Methods}

This article first does a review of the origin and development of environmental history and historical geography respectively. Then a comparison method is applied to analyze the similarities and differences between these two subjects. At last it argues that we can develop the writing of environmental history based on the studies of historical geography.

\section{The current state of Chinese environmental history}

The majority of Chinese researchers agree that environmental history first emerged as a distinct subfield of history in the United States in the early 1970s. According to

(c) The Author(s). 2016 Open Access This article is distributed under the terms of the Creative Commons Attribution 4.0 International License (http://creativecommons.org/licenses/by/4.0/), which permits unrestricted use, distribution, and reproduction in any medium, provided you give appropriate credit to the original author(s) and the source, provide a link to the Creative Commons license, and indicate if changes were made. 
Williams, American environmental history grew out of a tradition of political/conservation history and a scholarly tradition of intellectual history. [1] Prof. Perdue considered that the modern study of environmental history had two intellectual origins: the French Annales school which emerged in the early twentieth century; and American scholars in the 1970s who began to examine environmental change in the American frontier [2]. Roderick Nash, who first used the term "environmental history", defined environmental history as "the past contact of man with his total habitat". [3] In 1977, a group of American scholars first established The American Society for Environmental History (ASEH) and began to publish the journal of, Environmental Review (since 1998 known as Environmental History Review). The formation of this society and the issue of its own publication are a proof that environmental history has developed as a separate discipline in the United States since then.

The Chinese term “环境史 (environmental history)” was directly translated from English by some Chinese scholars such as Gao Dai, Hou Wenhui and Zeng Huabi in the 1990s [4]. In fact, publications including "environmental history" in there titles came out in China later than in the United States, as a result of both governmental and public increasing attention to environmental issues. In 1993, Academia Sinica of Taiwan and Australian National University jointly organized the Chinese Ecological Environment History Colloquium in Hong Kong and this is the first international conference on environmental history of China. After this conference, a book titled 积渐 所至: 中国环境史论文集 (Sediments of Time: Environment and Society in Chinese History) was published [5]. It included 24 conference papers authored by scholars mainly from Taiwan Area, Australia, the United States and France. Among them, many are famous scholars such as Mark Elvin from Australian National University, John R. McNeil from Georgetown Unviersity, Robert B. Marks from Whittier College, Rhoads Murphey from the University of Michigan, Pierre-Etienne Will from College De France, and Ts'ui-jung Liu from Academia Sinica of Taiwan. These papers can be grouped into five major themes: the research methods of environmental history; the effects of human activities on the change of the landscape and vegetation; history of epidemic diseases; people's knowledge and perception of nature; and the effects of policies on the processes of environmental change. While most contributors to 积渐所至: 中国环境史论文 集 mostly focus on the period from the Ming to the Qing dynasties, some of them go back to the Song or continue up to the present. These studies have played a leading role for future study of Chinese environmental history. From then on, Academia Sinica has held three related meetings respectively in 2002, 2006 and 2010. In 2005, Nankai University from mainland China also held a conference on environment and society in Chinese history and the proceedings was published two years later [6].

Nowadays, environmental history has become a hot sub-discipline of history in China. More and more scholars from historical geography, world history, social history, economic history and agricultural history have engaged in this field study. Institutions for environmental history study have been set up in many universities. As far as I know, there are at least five of them among which Central China Normal University was the first to establish its Center for Chinese Environmental History Study in November of 2006. Although Nankai University set up its research center two years later, it became the first university which admitted environmental history as an independent discipline divided into three fields of Chinese environmental history, foreign environmental 
history, and the history of disaster, disease and public health. Besides Renmin University of China, Beijing Normal University and Yunnan University also have created the similar research centers. Most of them are placed under history department.

In order to propose and promote the study of environmental history, Historical Research, the most authoritative journal of historical study in China, invited six scholars to write articles on the study of environmental history in the first volume of 2010. Among them, Zou Yilin proposed that the study of environmental history should pay attention to population and land use, the change of water environment in history, the impact of social system, the integrative study of social history and the environmental change within the last 1000 years. [7] Zhu Shiguang strongly suggested that the knowledge from ecology should be incorporated in this field and thus form "ecological environmental" history [8]. [9] Liu Ts'ui-jung argued that environmental history included ten basic topics.They were population and environment, land use and environmental changes, hydrological change, climate change and its effects, industrial development and environmental change, diseases and the environment, the relationships among gender, ethnic groups and the environment, attitudes toward nature and policies of resource exploitation, human settlements and "the built," or architectural environment and geographical information systems (GIS). Robert Marks considered that the main themes in China's environmental history should included changes in land use and land cover, climate change, water control, deforestation, colonization, the simplification of ecosystems, the sustainability of agriculture, China's ecological resilience, and comparative studies of environmental issues appeared after 1949 with those that had existed since 3000 years ago [10].

From the above introduction, we find that the themes of environmental history can differ due to different scholars' academic backgrounds and concerns. As a result it is quite challenging for us to summarize the current state of research in environmental history. To date, I can find only two summaries about environmental histories through the website of www.cnki.net, one of the most renowned academic websites in China. One was written by Zhang Guowang in 2003, and the other was written by Pan Mingtao in 2010. Zhang' review focused on natural environmental changes, including climate change, the changes in sea and land, desertification, changes in flora and fauna, hydrological changes, and the history of disasters, all of which are the subject of historical physical geography. The review of history of environmental changes was put at the end of the paper. [11] In fact, Zhang's paper is mostly about historical geography, a discipline I will discuss below. Based on Zhang's paper, Pan's review supplemented some papers concerning the themes proposed by Liu Ts'ui-jung and also added some other papers concerning ecological thinking, environmental awareness and its effects on culture, regionally integrative environmental changes, and environmental changes in southern China [12]. It is worth noticing that Nankai Journal has established special column for ecological and environmental history since 2006. In recent years, some scholars and publishers have engaged in the translation of works of environmental history. For instance, China Environmental Science Press has published a series of books under the title of Translation of Books Series of International Environment. All of these efforts have greatly promoted the study of environmental history in China.

\section{The relation between historical geography and environmental history}

Historical geography is mostly considered as a sub-discipline of geography in China. Traditionally, it was divided into historical physical geography and historical human 
geography. Under these two subdivisions, they were re-divided into many fields. It deals with changes of geographical environment since the Holocene era, ten thousand years ago, especially about four thousand years ago, including reconstructing the change processes and exploring the patterns and causes of changes to the land and landscapes. Modern historical geography originated from Yugong Association initiated by Gu Jiegang and Tan Qixiang in 1934, with its own publication of Yugong Semimonthly. This journal stopped in 1937 due to the invasion of Japanese armies and the study of historical geography also stagnated until the founding of People's Republic of China in 1949.

Historical physical geography has made great progress since 1949 because it would benefit the study of disasters prediction, hydraulic and other Infrastructural construction, and climate mitigation. From 1949 to 1980s, the most influential works included "A preliminary study of the climate fluctuations during the past 5000 years in China" authored by famous geographer and meteorologist Zhu Kezhen. Historical Physical Geography of China (Zhongguo lishi ziran dili 历史自然地理), edited by Tan Qixiang, Shi Nianhai and Chen Qiaoyi and published by Science Press in 1982. More than 20 scholars contributed to this volume, which represented the highest achievement of its time. The revised edition, published in 2013 by the same publisher, was edited by Zou Yilin and Zhang Xiugui and co-authored by other ten scholars.

Taken as a part of social sciences, historical human geography was considered useless and was deliberately neglected during this period. Until the 1980s, such an attitude was altered.

Since China's reform and opening up in the 1980s, historical geography in China has made even more remarkable achievements. These include:

1) The publishing of many historical atlas and dictionaries of historical place names. The most famous is The Historical Atlas of China (Zhongguo lishi ditu ji 中国历史 地图集) edited by Tan Qixiang from the Institute of Chinese Historical Geography, Fudan University. The 549-page atlas is divided into 8 volumes with 20 figure groups and 304 maps. It includes about 70,000 place names of cities, towns, rivers, mountains and other features, covering the period from the Neolithic era to the late Qing Dynasty (1644-1911), and an area larger than today's China. Historical Atlas of Earthquakes in China (Zhongguo lishi dizhen tuji 中国历史地震图集) was co-edited by the Institute of Geophysics of the China Earthquake Administration and the Institute of Historical Geography of Fudan University. It was published by SinoMaps Press between 1986 and 1990. It maps earthquakes recorded over 2700 years from the Neolithic era to the Qing Dynasty (1644-1911AD). The atlas details the epicenter, isoseismic line and intensity of each earthquake. It also includes other geographical features such as place names, administrative regions, mountains, rivers, lakes and coastlines at the time of each earthquake. It remains the most complete and authoritative atlas of historical earthquakes in China to date. The Atlas of the Distribution of Droughts and Floods in China over the Past 500 years (Zhongguo jin wubai nian han lao fenbu tuji, 中国近五百年旱涝分布图集) was edited by Chinese Academy of Meteorological Sciences of China Meteorological Administration and published by SinoMaps Press in 1982. The 510 pages of maps show the distribution of droughts and floods from 1470 to 1979 based on 2.2 million Chinese characters from over 2100 local gazetteers and other historical sources. It 
is widely cited in the study of climate change of China. The change of place names in history has always remained a focus in the study of historical geography. The most important dictionaries of historical place name include Dictionary of Chinese Historical Place Names (Zhongguo lishi diming cidian,中国历史地名词典) edited by the Institute of Historical Geography, Fudan University(1988), the Volume of Historical Geography within the Great Dictionary of Chinese History (Zhongguo lishi da cidian: lishi dili juan, 中国历史大辞典:历史地理卷) edited by Tan Qixiang(1996) and the Great Dictionary of Chinese Historical Place Names (Zhongguo lishi diming da cidian, 中国历史地名大词典) edited by Shi Weile (2005).

2) The study of historical human geography has made rapid progress as well. The most influential book series Immigration History of China (中国移民史), 6 volumes, edited by Ge Jianxiong and co-authored by Wu Songdi and Cao Shuji and published by the Fujian People's Publishing House in 1997; Population History of China (中国人口史) edited by Ge Jianxiong and co-authored with three scholars and published by Fudan University Press in 2002; and A General History of Administrative Subdivisions in China (中国行政区划通史) edited by Zhou Zhenhe and co-authored by 18 authors. Some of them have been published and others are continuing to be published.

3) With the application of the new methods and technologies, the study of climate change has more and more quantitative and integrative. The research data used to be only historical literature and archaeological data, but now researchers can use other natural evidence such as pollen, tree-ring, lake sediments and ice core for corroboration. Also the application of satellite image, Digital Terrain Model and ancient maps has improved the study of the change of land use and land cover.

Compared with the more sophisticated historical geography, environmental history is quite a young subject. Even for the definition of environmental history, scholars fail to agree with each other. For example, Nash [7] suggested that environmental history was simply "the past contact of man with his total habitat." [13] Donald Worster thought that environmental history dealt with the role nature played in human history. J. Donald Hughes even published a book entitled What Is Environmental History? After summarizing a variety of definitions of environmental history, Chinese scholar Bao Maohong gave his own definition: environmental history is the historical relation of people and human society to nature. Based on his explanation, a part of both nature and society because they have both biological properties and social attributes.

Environmental history is closely related with historical geography since both of them put the relation between the earth and human society as their priority. As Michael Williams [10] pointed out, "there is much in the concepts and phraseology of what environmental historians say which historical geographers will find familiar. It might even fill them with apprehension that many of the topics and emphases that are (or were) their prime concerns are presented as themes for environmental history, but with much more assurance and certainty that they are the core of the new subject". [1] Mark Elvin thought that there is no distinct division between historical geography and environmental history, the only difference being their academic culture. Chinese scholar Hou Yongjian argues that they differ from each other in the following four aspects: their name and origin; historical geography emphasizes environmental change while environmental history examines the relation of humans to their environment; human 
activities are considered as driving forces in the study of historical geography, while humans considered to be a part of the environment in environmental history; regional study is a common method in historical geography while reconstruction of the process of an event is important in environmental history [14].

I agree with Hou's point of view, but would add that their topics will differ sometimes. Since historical geography has developed for a much longer period and it has formed some traditional topics such as the change of administration divisions and boundaries, the change of population and cultural geography and the change of the river courses, the coastal lines and deserts.

Given the birth of environmental history was due to the increasing conflicts between human and nature in modern society, the main topics of environmental history are bound to different from historical geography. Environmental problems, such as pollution, resource depletion and excess wastes which seemed slightly in the past have greatly intensified in recent 30 years. Consequently, these issues should be the theme of environmental history.

Moreover, compared with environmental history, most historical geographic research in China is confined to the pre-1949 period, before the People's Republic of China was founded. In recent years there has been a tendency for regional studies of historical geography, through which researchers tend to integrate both historical physical geography and human geography in order to get better understanding of the relationship between human society and environmental changes. In contrast, environmental history mainly addresses problems and issues of contemporary relevance since the post-1949 period, which means that it not only studies some past environmental problems such as drought, flood, famine, but also addresses new environmental problems such as pollution brought about by the industrial development in China. In this case, some contents of these two subjects have overlapped but not all of them.

In summary, the aim of environmental history is to arouse the public's consciousness of today's worsening environmental situation. With the rapid industrial development in China, increased production and consumption both have dramatically caused severe environmental problems. Although the study of economics, sociology, and politics can contribute to understanding contemporary problems, environmental history makes it clearer that we need as well to place those issues in a broader and longer historical context.

\section{Future prospects of Chinese environmental history}

In respect of the reasons why environmental history emerged in other countries, some clues will be found to predict some future prospects for Chinese environmental history. The birth of environmental history in the United States resulted from the rise of an environmental protection movement as well as people's concern about the American frontier and wilderness. Environmental history in Germany originated from criticism and reflection of the application of nuclear technology in late 1970s. In India, when a sharp contradiction between modernization and local people's traditional way of using natural sources occurred, environmental history in India was called for to meet people's requirement of new history. The focus of environmental history in India thus concerned the history of forests and land use. The rise of environmental history in Australia had two causes. One was due to the development of historical geography in Australia. The other was due to the academic response to the increasingly severe 
environmental problems in Australia. In the 1970s, Australia was faced with deforestation, desertification and increasing numbers of natural disasters. Japanese environmental history developed from pollution history. After the Second World War, the Japanese economy developed rapidly but the industrial development all over Japan also brought about severe pollution of soil, air, and water, and people suffered with illnesses caused by pollution. Some Japanese residents initiated campaigns against the pollution with the help from scholars of engineering, medicine and social sciences. In Japan's case, these scholars became environmental historians to examine the origins of the environment problems Japan was facing [15].

In China today, pollution threatens public health and has become the most severe environmental problem. Recently, heavy haze and fog floating in the air in Beijing and other areas of China have been frequently reported and these reports have raised broad public awareness of environmental issues. Most developed countries have suffered pollution in the course of their industrialization, and these countries have begun to address, if not fully solved, their pollution problems. Scholars of Environmental history in China could learn from these countries' experiences and lessons and inform the public of them. In order to do this, we have better learn how to tell a good story, as the American environmental historian William Cronon wrote in his presidential address to the American Historical Association, a story that government and the public will listen to, making environmental history relevant and accessible to a wider public audience. [16] The findings of historical geographers can provide origins, processes and causes of environmental crises to help environmental historians to construct their stories which will help today's people understand how human activities in the past as well as in the present have affect the Earth's environment, including the quality of our soil, and water and air and how they should do to prevent further deterioration of the our environment.

\section{Results and discussion}

Though historical geography has developed much longer than environmental history in China and has evolved into a much sophisticated field with certain research topics, environmental history is closely related with historical geography because both of them put the relation between the earth and human society as their priority. However, their research aims differs in some extent. Many topics of historical geography are more academic than practical. While the aim of environmental history is to arouse the consciousness of the public of today's worsening environmental problems, most of which are new issues came out hand-in-hand with the rapid development in recent decades. With the rapid industrial development in China, increased production and consumption both have dramatically caused severe environmental problems. Although the study of economics, sociology, and politics can contribute to understanding and solving contemporary problems, environmental history makes it clearer that we need as well to place those issues in a broader and longer historical context. The findings of historical geographers can provide origins, processes and causes of environmental crises to help environmental historians to construct their stories.

\section{Conclusion}

With historical narrative and comparison methods, this article has reviewed the development of environmental history and historical geography in China. The origins and 
main research interests of these two subjects are also discussed. It concludes that though both of them put the relation between the earth and human society as their priority and is closely related with each other, they belong to different subject. The findings of historical geographers can provide origins, processes and causes of environmental crises to help environmental historians to construct their stories which will help today's people understand how human activities in the past as well as in the present have affect the Earth's environment and how they should do to prevent further deterioration of the our environment.

\section{Acknowledgment}

This research has been sponsored by National Science Foundation of China (41371151) and Shanghai Pujiang Program (12PJC077). I would like to thank Prof. Robert B. Marks for suggestions on drafts of this paper.

\section{Competing interests}

The author declare that she has no competing interests.

Received: 12 April 2016 Accepted: 19 August 2016

Published online: 28 November 2016

\section{References}

1. Williams M (1994) The relation of environmental history and historical geography. J Hist Geogr 20(1):3-21

2. Peter C (2012) Perdue's lecture at Fudan University., June

3. Nash R (1972) American environmental history: a new teaching frontier, the. Pac Hist Rev 41(3):362-372

4. Bao M (2012) The origin and development of environmental history. University Press, Beijing, p 157

5. Liu T'u-j, Mark E (1995) Sediments of Time: Environment and Society in Chinese History. Institute of Economics of Academia Sinica, Taiwan

6. Wang Lihua eds (2007) The environment and society in Chinese history, Shenghuo-Dushu- Xinzhi Sanlian Bookstore.

7. Yilin Z (2010) Some issues related with the study of environmental history. Hist Res 1:15-18

8. Zhu S (2010) Deepening the study of ecological environmental history following the rule of human-Earth relationship. Hist Res 1:4-10

9. Liu Ts'ui-jung (2006) On Chinese environmental history, Nankai J 2.

10. Marks RB (2012) Its Environment and History. Rowman \&Littlefiled Publishers, Inc, China, pp 332-337

11. Zhang Guowang (2003) A review of studies of Chinese environmental history in recent years, Research Trend in Chinese History, 3

12. Pan Mingtao (2012) A review of studies of Chinese environmental history in 2010, Research Trend in Chinese History, 1.

13. Nash R (1972) American environmental history: a new teaching frontier. Pac Hist Rev 41:362-372

14. Hou Yongjian (2011) An exploration of historical geography, pp. 149-169, China Social Sciences Press, 12

15. Bao M (2012) The origin and development of environmental history. Press, Beijing University

16. William Cronon (2013) "Story Telling: Presidential Address," The American Historical Review: 1-19

\section{Submit your manuscript to a SpringerOpen ${ }^{\circ}$ journal and benefit from:}

- Convenient online submission

- Rigorous peer review

- Immediate publication on acceptance

- Open access: articles freely available online

- High visibility within the field

- Retaining the copyright to your article

Submit your next manuscript at $\downarrow$ springeropen.com 